\title{
Sustaining Collusion under Economic Integration
}

\author{
Luca Colombo $^{1} \quad$ Paola Labrecciosa ${ }^{2}$
}

March 14, 2005

\footnotetext{
${ }^{1}$ Corresponding Author. Institute for International Integration Studies, The Sutherland Centre, Trinity College Dublin, Dublin 2, Ireland; email: colombol@tcd.ie; tel. +353-16082228. Dept. of Economics, University of Bologna, Strada Maggiore 45, 40125 Bologna, Italy, email: colombo@spbo.unibo.it; tel. +39-051-2092613.

${ }^{2}$ Dept. of Economics, Trinity College Dublin, Dublin 2, Ireland; email: labreccp@tcd.ie; tel. +353-1-6082325. Dept. of Economics, University of Bologna, Strada Maggiore 45, 40125 Bologna, Italy, email: labrecciosa@spbo.unibo.it; tel. +39-051-2092660.
} 


\begin{abstract}
In this paper, we aim at investigating from a game theory perspective first whether trade liberalization can promote a collusive intra-industry trade and secondly whether such a collusive trade is always socially desirable compared to the autarchy solution. We show that, under Cournot competition, economic integration is anti-competitive if collusive trade can be a possible outcome of the repeated game. Under price competition, the likelihood of collusive trade is a necessary but not sufficient condition for trade liberalization to be pro-competitive. Furthermore, we show that there exists a parameter region where economic integration enhances cartel stability no matter firms' strategic variable.
\end{abstract}

JEL Classification: F12, F15, L13.

Key Words: cartel stability, trade liberalization, trade costs, multimarket contact, oligopoly. 


\section{Introduction}

According to the World Trade Organization and the World Bank Group, a growing proportion of cartel agreements is international in scope. ${ }^{1}$ A good indicator of such an international dimension of cartels is the overwhelming number of collusive agreements involving international firms prosecuted by the US Department of Justice in the 1990s.

To be considered international, a cartel must involve more than one producer; include firms from more than one country; have attempted to set prices or divide markets in more than one country. The industry evidence on the 1990s international cartels suggests that they operated in a variety of industries, including chemicals, metals, paper products, transportation, and services. Moreover, it seems that they were formed as a result of increasing competition and market integration (see Evenett et al., 2004).

In this paper, we aim at investigating from a game theory perspective first, whether trade liberalization can promote a collusive intra-industry trade and secondly, whether such a collusive trade is always socially desirable compared to the autarchy solution.

Under the assumptions of a constant returns to scale production function and homogeneous good, the existing literature investigating the effects of trade liberalization on the stability of international cartels assumes that collusion is enforced by the understanding to sell only into the domestic market. Pinto (1986), in a repeated game version of the Brander and Krugman's model (1983), shows that such an understanding is optimal for firms in terms of joint profit maximization, i.e. it represents an efficient outcome neither firm can improve upon acting unilaterally. As a consequence, if international trade is observed, firms are not sustaining any collusive agreements. Fung (1991; 1992), first shows that a theoretical possibility for implicit collusion to be associated with international trade occurs when products are differentiated. ${ }^{2}$

\footnotetext{
${ }^{1}$ WTO Annual Report, 1997, p.40 and Evenett et al. (2004).

${ }^{2}$ In a setting with differentiated products, Colonescu and Schmitt (2003) address the issue of collusive sustainability with multimarket contact. On collusion with multimarket contact see also
} 
In this paper, we provide a model of intra-industry trade that can allow implicit collusion to arise as a possible outcome of the repeated game even when international trade takes place, keeping the assumption of homogeneous good. Indeed, if the assumption of differentiated goods is surely appropriate for many industries, in many others where collusive trade has been documented, homogeneity in goods seems a better description of reality. For instance, the food additive cartel, the vitamin cartel, the graphite electrodes cartel, the lysine cartel and the plasterboard cartel, to mention a few, all active in the 1990s and prosecuted by the US Justice Department or the European Commission, are cartels made up by international firms selling almost completely standardized products. ${ }^{3}$

An additional possible drawback of the existing literature dealing with trade liberalization and international collusion is that it focuses on constant returns to scale production functions, exclusively. Yet, economies of scale are non negligeable in many industries where firms seem to behave cooperatively, either by setting prices or quantities. ${ }^{4}$ Furthermore, firms engaged in international collusion are usually large corporations, and diseconomies of scale surely influence their performance, as recognized by Williamson $(1975 ; 1985)$ and Riordan and Williamson $(1985) .^{5}$

Our main goal is to provide a theoretical appraisal of the possibility that trade liberalization may increase the scope for collusive trade, assuming away constant returns to scale as well as product differentiation. Throughout the paper, we focus on the s.c. hard core cartels, made up of private producers from at least two countries Bernheim and Whinston (1990).

${ }^{3}$ In general, it seems that products exchanged across E.U. borders are sufficiently similar to make Fung's arguments empirically irrelevant to european integration (see Smith and Venables, 1988).

${ }^{4}$ The analysis of scale economies in models of international trade with imperfect competition can be found in Krugman (1979), Ethier and Horn (1984), Helpman and Krugman (1985), Smith and Venables (1988) and Krugman (1991). However, the possibility that firm behave cooperatively is not considered.

${ }^{5}$ Based on Williamson's categorization, there are four types of diseconomies of scale: atmospheric consequences due to specialization, bureaucratic insularity, incentive limits of the employment relation and communication distortion due to bounded rationality. Generally, these diseconomies of scale increase with firm size. 
who cooperate to control prices or allocate shares in world markets. ${ }^{6}$ As usual in the literature, we consider trade liberalization as a reduction in per unit trade costs, namely, transport costs, specific tariffs (particularly relevant on agricultural products), ad valorem tariffs on intermediate goods (see Mujundra, 2004), regardless of whether the cuts are large or small. ${ }^{7}$

Looking at the existing related literature dealing with intra-industry trade, whether economic integration is pro-competitive depends on several factors, among which the type of market competition, price or quantity, the nature of products, imperfect or perfect substitutes, the prescribed penal codes, trigger strategies or optimal punishments and the definition of trade costs. ${ }^{8}$ To our knowledge, how scale economies affect the relationship between trade costs and the stability of international collusion is an open issue.

The paper closer to ours is probably Lommerud and Sorgard (2001). They consider both price and quantity competition in an infinitely repeated duopoly game with perfect substitutes and constant returns to scale production function, showing that, under quantity competition, a reduction in per unit trade costs is always pro-competitive, while under price competition, the opposite holds true. ${ }^{9}$ The main difference with respect to our analysis is that they assume that for each firm collusion consists in selling only into the domestic market. In their setting, this corresponds to the solution of joint profit maximization, i.e. it constitutes a strong Nash equilibrium of the repeated game. However, we show that it may become optimal for firms to start a two-way trade during the collusive phase, as the production function

\footnotetext{
${ }^{6}$ Hard core cartels differ form export cartels, where private or state run firms from one country agree to fix prices or market shares in export markets, but not in their domestic market.

${ }^{7}$ Two different types of trade costs are ad valorem and fixed trade costs. The former include tariffs, insurance costs, exchange rate risks; the latter account for costs of product certification, adjustments to local regulation, costs of maintaining a distribution network, foreign red tape.

${ }^{8}$ Davidson (1984), Rotemberg and Saloner (1989) and Fung (1992) address the issue whether trade liberalization enhances cartel stability, assuming that firms compete only in one country. Two-way trade, either collusive or not, is not considered.

${ }^{9}$ The authors adopt also Abreu's (1986) optimal punishments, showing that the conclusion on price competition is reversed.
} 
exhibits sufficiently decreasing returns to scale. In contrast to Lommerud and Sorgard (2001), we find that the collusive profits may depend on the level of trade costs and that the occurrence of collusive trade is crucially responsible for a new set of results. In particular, we show that, under Cournot competition, economic integration is anti-competitive if collusive trade may arise as a possible outcome of the repeated game. Under price competition, the likelihood of collusive trade is a necessary but not sufficient condition for trade liberalization to be pro-competitive. Furthermore, we show that there exists an economically meaningful parameter region where economic integration enhances cartel stability no matter firms' strategic variable. When scale economies come into the picture, the results we are accustomed with from Lommerud and Sorgard (2001), which are related to those derived by Pinto (1986), may be inverted. This should not be too surprisingly, since the incentives to collude are directly linked to the incentives of restricting outputs, which depend also on the shape of the cost function. As a consequence, it seems not plausible to get rid of scale economies in analyzing the incentives for firms to take part in international cartels, as well as in signing the relationship between trade liberalization, i.e. reduction in trade costs, and the stability of international cartels.

The remainder of this paper is structured as follows. The model is laid out in Section 2. Section 3 deals with quantity competition, while Section 4 deals with price competition. The two settings are compared in Section 5. Section 6 contains a welfare appraisal, while concluding remarks are in Section 7.

\section{The Model}

Two firms, firm $a$ located in country $A$ and firm $b$ located in country $B$, are engaged in quantity (Cournot) or price (Bertrand) competition over an infinite time horizon. Let $q_{i}$ and $q_{i}^{*}$ denote the output that firm $i=\{a, b\}$ produces for domestic and foreign consumption, respectively. In each country, the inverse demand function is given by:

$$
p_{j}=1-Q_{j}, \quad j=\{A, B\}
$$


where $Q_{A}=q_{a}+q_{b}^{*}$ and $Q_{B}=q_{b}+q_{a}^{*}$ stand for industry output in country $A$ and $B$, respectively. On the supply side, we relax the usual assumption of constant returns to scale, by considering the following production cost function:

$$
c_{i}\left(q_{i}, q_{i}^{*}\right)=\alpha\left(q_{i}+q_{i}^{*}\right)+\frac{\beta}{2}\left[q_{i}^{2}+\left(q_{i}^{*}\right)^{2}\right], \quad i=\{a, b\}
$$

which can accommodate decreasing, constant or increasing returns to scale, depending on the value assumed by the scale economies parameter, $\beta$. If $\beta>(<) 0$ returns are decreasing (increasing), while they are constant if $\beta=0 .{ }^{10}$. To save space, without any loss of generality (since cartel stability is not affected) let us normalize $\alpha$ to zero. Trade is associated with per unit trade costs $\tau$ incurred in exporting goods from one country to the other, with $0<\tau<1 / 2$ for collusion being always profitable. Under price competition, if $\tau \geq 1 / 2$ then Nash profits and collusive profits coincide, meaning that no room is left for collusive agreements. Trade costs can be thought as transportation costs and/or specific tariffs, for instance tariffs levied on intermediate goods (see Mujundar 2004). As usual in the literature, we interpret economic integration as a reduction in these trade costs.

We model firms interaction in the market as a repeated price or quantity game over an infinite time horizon. Following Friedman (1971) and Fudenberg and Maskin (1986), each firm sticks to the cooperative strategy as long as the rival does likewise. If a deviation is detected, say at time $t$, both firms revert to the one shot Nash equilibrium strategy from time $t+1$ onwards. Collusion can be sustained as a subgame perfect equilibrium of the infinitely repeated game if the discount factor $\delta \in(0,1]$, common to both firms, is larger than a critical threshold given by $\widehat{\delta}_{K}=\left(\pi_{K}^{D}-\pi^{C}\right) /\left(\pi_{K}^{D}-\pi_{K}^{N}\right)$, where superscripts $D, C$ and $N$ stand for deviation, collusion and Nash respectively, while the subscript $K=\{P, Q\}$ denotes the kind of market competition, price or quantity.

Throughout the paper, we consider full cartelization, i.e. during the collusive phase, the cartel acts as a unique firm aimed at maximizing the sum of the profits that

\footnotetext{
${ }^{10} \mathrm{It}$ is worth noting that $(2)$ does not allow for scope economies, since $c_{i}\left(q_{i}, q_{i}^{*}\right)=c_{i}\left(q_{i}\right)+c_{i}\left(q_{i}^{*}\right)$. The reason is that we want to focus on the effects of scale economies in isolation. As a remainder, economies (diseconomies) of scope are present if $c_{i}\left(q_{i}, q_{i}^{*}\right)<(>) c_{i}\left(q_{i}\right)+c_{i}\left(q_{i}^{*}\right)$.
} 
each individual firm obtains from selling at home and abroad. Under the assumption of constant returns to scale, the joint profits maximization yields a solution without trade. However, collusion can be sustained not necessarily staying at home. Indeed, collusion can be associated with trade whenever the maximization of joint profits yields inner solutions, meaning that each firm produces a strictly positive quantity for the foreign market. In formal terms, the cartel's maximization problem writes:

$$
\mathcal{P}\left\{\begin{array}{l}
\max _{\left\{q_{i}, q_{i}^{*}\right\}}\left\{\pi_{a}+\pi_{b}\right\} \\
\text { s.t. } q_{i} \geq 0, q_{i}^{*} \geq 0, \quad i=\{a, b\}
\end{array}\right.
$$

where $\pi_{a}=p_{A} q_{a}+\left(p_{B}-\tau\right) q_{a}^{*}-c_{a}$ and $\pi_{b}=p_{B} q_{b}+\left(p_{A}-\tau\right) q_{b}^{*}-c_{b}$. When inner solutions to $\mathcal{P}$ exist, per firm collusive quantity and the price level in each country are given by: ${ }^{11}$

$$
q_{i}^{C}=\frac{\beta+2 \tau}{\beta(4+\beta)} ; \quad q_{i}^{* C}=\frac{\beta-(\beta+2) \tau}{\beta(4+\beta)} ; p^{C}=\frac{2+\beta+\tau}{4+\beta}
$$

with $\beta>\widehat{\beta}=2 \tau /(1-\tau)$ for $q_{i}^{* C}>0$, i.e. for the likelihood of collusive trade to exist. Otherwise, firms sustain a collusive agreement consisting in not exporting into each other domestic market, i.e. $q_{i}^{* C}=0$. When no trade takes place in the collusive phase, each firm acts as a monopolist at home selling $q_{i}^{C}=1 /(2+\beta)$ at a price $p^{C}=(1+\beta) /(2+\beta)$. The individual collusive profit amounts to:

$$
\pi_{i}^{C}= \begin{cases}\frac{2 \tau^{2}+\beta[2+(\tau-2) \tau]}{2 \beta(4+\beta)}, & \text { with collusive trade } \\ \frac{1}{2(2+\beta)}, & \text { without collusive trade }\end{cases}
$$

Notice that $\tau$ enter into the expression of $\pi_{i}^{C}$ only when collusive trade occurs.

Proposition 1 If returns to scale are sufficiently decreasing, i.e. $\beta>\widehat{\beta}$, collusive trade may arise. Otherwise, collusive trade does not exist.

\section{$3 \quad$ Quantity Setting}

In this section, we examine the case of quantity competition. Suppose one firm decides to break down the international cartel. The one period deviation quantity

\footnotetext{
${ }^{11}$ Throughout the paper, second order conditions are always satisfied. They are omitted for brevity.
} 
has to be computed given that the rival's production corresponds to the individual collusive level. We have to distinguish between two scenarios, depending on whether the likelihood of collusive trade exists.

Consider first $\beta>\widehat{\beta}$, which is the case in which colluding firms are selling both at home and abroad. The cheating firm's objective function writes:

$$
\pi_{i}=\left(1-q_{i}^{D}-q_{j}^{* C}\right) q_{i}^{D}-\frac{\beta\left(q_{i}^{D}\right)^{2}}{2}+\left(1-q_{i}^{* D}-q_{j}^{C}-\tau\right) q_{i}^{* D}-\frac{\beta\left(q_{i}^{* D}\right)^{2}}{2}
$$

which can be maximized with respect to $q_{i}^{D}$ and $q_{i}^{* D}$. Solutions are given by:

$$
q_{i}^{D}=\frac{2 \tau+\beta(3+\beta+\tau)}{\beta(2+\beta)(4+\beta)} ; q_{i}^{* D}=\frac{\beta(3+\beta)-[2+\beta(4+\beta)] \tau}{\beta(2+\beta)(4+\beta)}
$$

Notice that $q_{i}^{D}>q_{i}^{* D}$ in the entire parameter range. The domestic deviation quantity is always higher than the deviation quantity abroad. By plugging (6) into (5), the overall deviation profit obtains:

$$
\pi_{i, Q}^{D}=\frac{2 \beta^{2}(3+\beta)^{2}(1-\tau)+\{8+\beta(4+\beta)[5+\beta(4+\beta)]\} \tau^{2}}{2 \beta^{2}(2+\beta)(4+\beta)^{2}}
$$

Now, consider $\beta \leq \widehat{\beta}$. The collusive agreement consists in selling only into each domestic market, and no collusive trade takes place. Since the monopoly profit at home is guaranteed, deviation has to be computed by looking at the foreign market only. The cheating firm has to set the export quantity, $q_{i}^{* D}$, given that the rival continues to play the collusive strategy. The cheating firm's objective function can be thought as:

$$
\pi_{i}=\frac{1}{2(2+\beta)}+\left(1-q_{i}^{* D}-\frac{1}{2+\beta}-\tau\right) q_{i}^{* D}-\frac{\beta\left(q_{i}^{* D}\right)^{2}}{2}
$$

which can be maximized with respect to $q_{i}^{* D}$. The solution turns out to be:

$$
q_{i}^{* D}=\frac{1+\beta-2 \tau-\tau \beta}{(2+\beta)^{2}}
$$

Accordingly, the overall deviation profit is:

$$
\pi_{i}^{D}=\frac{2 \beta^{2}-2 \beta^{2} \tau+\tau^{2} \beta^{2}+6 \beta-6 \tau \beta+4 \tau^{2} \beta+4 \tau^{2}-4 \tau+5}{2(2+\beta)^{3}}
$$


Once a deviation is detected, each firm moves back to the Cournot-Nash equilibrium. Routine computations lead to the following equilibrium quantities:

$$
q_{i}^{N}=\frac{1+\beta+\tau}{(3+\beta)(1+\beta)} ; q_{i}^{* N}=\frac{1+\beta-(2+\beta) \tau}{(3+\beta)(1+\beta)}
$$

with $\beta>(2 \tau-1) /(1-\tau)$ for $q_{i}^{* N}>0$. However, since $\widehat{\beta}>(2 \tau-1) /(1-\tau)$, if collusive trade exists then $q_{i}^{* N}>0$ always. The one shot Nash equilibrium profit amounts to:

$$
\pi_{i, Q}^{N}=\frac{(2+\beta)\left\{2(1+\beta)^{2}(1-\tau)+[5+\beta(4+\beta)] \tau^{2}\right\}}{2(3+\beta)^{2}(1+\beta)^{2}}
$$

By using all the relevant profits expressions, we are in a position to compute the critical discount factor, $\widehat{\delta}_{Q}$. It is well known that collusion can be sustained as a subgame perfect equilibrium of the infinitely repeated game iff the discount factor $\delta \in(0,1]$, which, given the symmetry assumption, is common to both firms, is larger than $\widehat{\delta}_{Q}$ (the expression of $\widehat{\delta}_{Q}$ is provided in the Appendix).

Now, let us check how a change in per unit trade costs $\tau$ affects the critical discount factor:

$$
\begin{aligned}
& \frac{\partial \widehat{\delta}_{Q}}{\partial \tau} \leq 0, \forall \beta \leq \widehat{\beta} \\
& \frac{\partial \widehat{\delta}_{Q}}{\partial \tau}>0, \forall \beta>\widehat{\beta}
\end{aligned}
$$

Proposition 2 In the quantity setting, if the likelihood of collusive trade exists, any economic integration enhances cartel stability. Otherwise, the opposite holds true.

\section{Price Setting}

We assume competition takes place in prices. The optimal deviation consists in setting the price level equal to $p^{C}-\varepsilon$, with $\varepsilon \rightarrow 0$. In doing so, the cheating firm earns the monopoly profits both at home and abroad. As before, we have to distinguish between two scenarios, depending on whether the likelihood of collusive trade exists:

$$
\pi_{i}^{D}=\left\{\begin{array}{l}
\frac{2(2-\tau)^{2}}{(4+\beta)^{2}}, \quad \forall \beta>\widehat{\beta} \\
\frac{1-\tau}{\beta+2}, \quad \forall \beta \leq \widehat{\beta}
\end{array}\right.
$$


During the punishment phase, each firm reverts to the one shot Nash equilibrium strategy. The stage game is a Bertrand game with asymmetric costs, since the cost of selling abroad is augmented by $\tau$. As a consequence, as in the constant returns to scale case, no trade arises after a deviation has been detected, implying that each firm earns a positive profit only by serving the domestic market. The equilibrium price level can be computed by setting the rival's profits from exports equal to zero, that is $(p-\tau)(1-p)-\beta / 2(1-p)^{2}=0$. The admissible solution is:

$$
p^{N}=\frac{\beta+2 \tau}{2+\beta}
$$

which is admissible as long as $\tau<1 / 2$. If $\tau$ were higher than $1 / 2$, the BertrandNash and the collusive profits would coincide, meaning that the critical discount factor would approach 1, leaving no room for any collusive agreements. The resulting Bertrand-Nash profits are:

$$
\pi_{i}^{N}=\frac{2 \tau(1-\tau)}{2+\beta}
$$

By using all the relevant profits expressions, we compute $\widehat{\delta}_{P}$, the lowest discount factor for which collusion is sustainable (the expression of $\widehat{\delta}_{P}$ is provided in the Appendix). A change in per unit trade $\operatorname{costs} \tau$ affects $\widehat{\delta}_{P}$ as follows:

$$
\begin{aligned}
& \frac{\partial \delta^{P}}{\partial \tau} \propto \Omega, \forall \beta>\widehat{\beta} \\
& \frac{\partial \delta^{P}}{\partial \tau} \geq 0, \forall \beta \leq \widehat{\beta}
\end{aligned}
$$

where $\Omega=\left\{4(3 \tau-2)[\tau-\beta(1-\tau)]-\beta^{2}[2-\tau(4-\tau)]\right\}$, which is positive if: ${ }^{12}$

$$
\beta<\widetilde{\beta}=2 \frac{3 \tau^{2}-5 \tau+2+(1-2 \tau) \sqrt{3 \tau^{2}-8 \tau+4}}{2-4 \tau+\tau^{2}}
$$

Proposition 3 In the price setting, if there are sufficiently decreasing returns to scale, i.e. $\beta>\widetilde{\beta}$, any economic integration hinders cartel stability. Otherwise, the opposite holds true.

\footnotetext{
${ }^{12}$ The other root is not relevant to the analysis, since it belongs to the region in which no collusive trade arises. Formally, $\widehat{\beta}>2 \frac{3 \tau^{2}-5 \tau+2-(1-2 \tau) \sqrt{3 \tau^{2}-8 \tau+4}}{2-4 \tau+\tau^{2}}$.
} 


\section{Price vs Quantity}

From a direct comparison between price and quantity competition, we can state:

Proposition 4 If $\beta \in(\widehat{\beta}, \widetilde{\beta})$, irrespectively of whether competition takes place in prices or quantities, any economic integration enhances cartel stability.

The following figure summarizes all the relevant results.

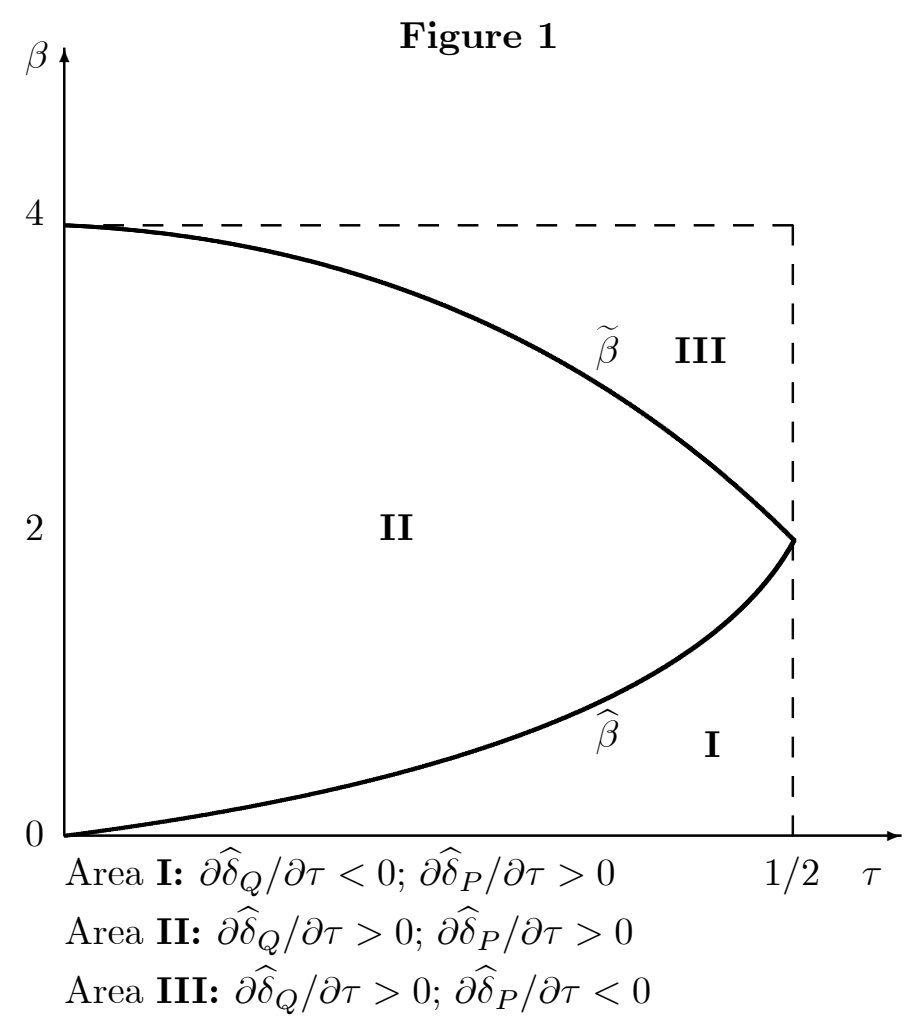

It is worth noting that without collusive trade (Area I), economic integration turns out to be pro-competitive under quantity competition and anti-competitive under price competition. When the possibility of collusive trade is taken into account, which in our model is equivalent to considering sufficiently decreasing returns to scale (Area II), a reduction in trade costs is anti-competitive both under price and quantity competition. Quite interestingly, as soon as the economies of scale parameter reaches a certain threshold, given by $\widetilde{\beta}$ (Area III), economic integration is pro-competitive under price competition and anti-competitive under quantity competition, exactly 
the opposite result we get in absence of collusive trade. Moreover, by looking at Figure 1, we notice that:

Lemma 1 Under quantity competition, for any given $\beta \in(0,2)$, there exists a non monotone relationship between $\widehat{\delta}_{Q}$ and $\tau$; under price competition, for any given $\beta \in(2,4)$, there exists a non monotone relationship between $\widehat{\delta}_{P}$ and $\tau$.

In case of a non monotone relationship between the critical discount factor and the level of trade costs, the derivative of $\widehat{\delta}_{K}$ with respect to $\tau$ is first increasing and then decreasing, with $K=\{P, Q\}$. Therefore, a level of trade costs exists such that the scope for collusion is minimized.

\section{Welfare Appraisal}

In this section, we investigate whether two-way trade with collusion is always socially desirable compared to the alternative of no trade. What we know from the existing analyses based on static models is that open up to trade is always welfare improving. When international trade is not allowed, each firm acts as a monopolist in its own country. This scenario should be compared to the one in which trade liberalization is accompanied by the formation of an international hard core cartel.

In case of autarchy, welfare is given by:

$$
W^{A}=\frac{3+\beta}{2(\beta+2)^{2}}
$$

where the superscript $A$ stands for autarchy. Notice that $W^{A}$ is obviously independent from $\tau$.

In case of two-way trade with collusion, the expression of welfare writes:

$$
W^{C T}=\pi_{i}^{C}+C S+\tau q_{i}^{* C}
$$

where $C S=(\tau-2)^{2} /\left[2(4+\beta)^{2}\right]$ is the level of consumers' surplus and $\tau q_{i}^{* C}$ is the amount of tax revenues.

From a direct comparison between (17) and (18) we can state: 
Proposition 5 Welfare in autarchy is always lower than welfare associated with collusive intra-industry trade.

\section{Concluding Remarks}

In this paper, we have investigated from a game theory perspective whether reduced trade barriers can promote a collusive intra-industry trade and whether such a collusive trade is always socially desirable compared to the autarchy solution. Under the assumptions of a constant returns to scale production function and homogeneous good, the existing literature investigating the effects of trade liberalization on the stability of international cartels assumes that collusion is enforced by the understanding to sell only into the domestic market. To our knowledge, homogeneity in good has never been associated with collusive two-way trade. By relaxing the assumption of constant returns to scale, our analysis has unveiled that implicit collusion among international firms can take the form of collusive two-way trade, depending on the nature of production costs. We have shown that a necessary condition for collusive trade to arise is that returns to scale are sufficiently decreasing. Otherwise collusive trade does not exist. In the quantity setting, if collusive trade may exist, any economic integration enhances cartel stability. Otherwise, the opposite holds true. This is in contrast with the conventional wisdom, according to which, if quantity competition prevails, then the reduction in trade barriers is always pro-competitive. We have shown that even the slightest presence of diseconomies of scale yields a non monotone relationship between the critical discount factor and the level of trade costs. Under price competition, if the production technology exhibits sufficiently decreasing returns to scale, any economic integration hinders cartel stability. Otherwise, the opposite holds true. From a comparison between the two settings, we have found a parameter region where any economic integration enhances cartel stability irrespectively of whether competition takes place in prices or quantities. Finally, from a policy perspective, we have proven that open up to trade is always socially desirable even if collusive trade arises. 
The key message of our paper is that economic integration does not automatically provide the necessary competitive discipline, implying that competition policy should be even more vigilant as markets become more integrated. All the possible beneficial effects of trade liberalization may be partially offset by the negative effects ascribed to international collusion. 


\section{Appendix}

Critical discount factor in case of quantity competition:

$$
\widehat{\delta}_{Q}=\frac{(1+\beta)^{2}(3+\beta)^{2}\left(8 \tau+4 \beta \tau^{2}+\beta^{2}(2+(-2+\tau) \tau)\right)}{2 \beta^{2}(1+\beta)^{2}(17+2 \beta(6+\beta))(1-\tau)+\Omega \tau^{2}}, \forall \beta>\widehat{\beta}
$$

where $\Omega=(72+\beta(4+\beta)(93+\beta(4+\beta)(27+2 \beta(4+\beta))))$

$$
\widehat{\delta}_{Q}=\frac{(1+\beta-2 \tau-\tau \beta)(3+\beta)^{2}(1+\beta)^{2}}{2 \beta^{4}+3 \tau \beta^{3}+13 \beta^{3}+18 \beta^{2} \tau+31 \beta^{2}+35 \tau \beta+33 \beta+22 \tau+13}, \quad \forall \beta \leq \widehat{\beta}
$$

Critical discount factor in case of price competition:

$$
\begin{gathered}
\widehat{\delta}^{P}=\frac{(2+\beta)\left\{2(4-\beta) \beta(1-\tau)-[8+\beta(2+\beta)] \tau^{2}\right\}}{4 \beta[3 \tau-2-\beta(1-\tau)][(6+\beta) \tau-4]}, \beta>\widehat{\beta} \\
\widehat{\delta}^{P}=\frac{1}{2(1-\tau)}, \quad \beta \leq \widehat{\beta}
\end{gathered}
$$




\section{References}

[1] Abreu, D. (1986), Extremal Equilibria of Oligopolistic Supergames, Journal of Economic Theory, 39, 191-225.

[2] Bernheim, B. D. and M. D. Whinston (1990), Multimarket Contact and Collusive Behavior, Rand Journal of Economics, 21, 1-26.

[3] J. Brander and P. Krugman (1983), A Reciprocal Dumping Model in International Trade, Journal of International Economics, 15, 313-321.

[4] C. Colonescu and N. Schmitt, (2003), Market Segmentation, Market Integration and Tacit Collusion, Review of International Economics, 11, 175-192.

[5] Davidson, C. (1984), Cartel Stability and Tariff Policy, Journal of International Economics, 17, 219-37.

[6] Ethier, W. and H. Horn (1984), A New Look at Economic Integration, in Kierzkowsky, H., Monopolistic Competition and International Trade, Oxford University Press, 207-29.

[7] Friedman, J.W. (1971), A Non-Cooperative Equilibrium for Supergames, Review of Economic Studies, 28, 1-12.

[8] Fudenberg, D., and E. Maskin (1986), The Folk Theorem in Repeated Games with Discounting or with Incomplete Information, Econometrica, 54, 533-554.

[9] Fung, K.C. (1991), Collusive Intra-Industry Trade, Canadian Journal of Economics, 24, 391-404.

[10] Fung, K.C. (1992), Economic Integration as Competitive Discipline, International Economic Review, 33, 837-47.

[11] Helpman, E. and P. Krugman (1985), Market Structure and Foreign Trade : Increasing Returns, Imperfect Competition and the International Economy, Cambridge, Mass., MIT Press. 
[12] Krugman, P. (1979), Increasing Returns, Monopolistic Competition and International Trade, Journal of International Economics, 9, 469-79.

[13] Krugman, P. (1991), Geography and Trade, Cambridge, Mass., MIT Press.

[14] K. E. Lommerud and L. Sørgard (1999), Trade Liberalization and Cartel Stability, Review of International Economics, 9, 343-355.

[15] S. Mujundar (2004), Revenue Implications of Trade liberalization under Imperfect Competition, Economics Letters, 82, 83-89.

[16] B. Pinto (1986), Repeated Games and the Reciprocal Dumping Model of Trade, Journal of International Economics, 20, 357-366.

[17] Riordan, M.H. and O.E. Williamson (1985), Asset Specificity and Economic Organization, International Journal of Industrial Organization, 3, 365-378.

[18] Rotemberg, J. and G. Saloner (1989), Tariffs vs. Quotas with Implicit Collusion, Canadian Journal of Economics, 22, 237-44.

[19] P. J.H. Schröder (2004), Cartel Stability and Economic Integration, DIW Berlin Discussion Papers.

[20] Smith, A. and A. Venables (1988), Completing the Internal Market in the EC : Some Industry Simulations, European Economic Review, 32, 1501-25.

[21] Williamson, O.E. (1975), Markets and Hierarchies: Analysis and Antitrust Implications, New York:Free Press.

[22] Williamson, O.E. (1985), The Economics Institutions of Capitalism, New York:Free Press. 